\title{
Sustainable urban transport in Lithuania: influence of land use and socio-economic development
}

\author{
Z. Bazaras, A. Kersys, R. Kersys \& R. Skvireckas \\ Department of Transport Engineering, Kaunas University of Technology, \\ Lithuania
}

\begin{abstract}
For sustainable urban transport planning, instead of the direct prediction of transport demand based on tendency prognosis, the connection between influential factors and demand is modeled. The prognosis of influential factors used takes into account the reasons behind public transport demand. Practical realization of such a task demands a detailed analysis of the influence of these factors on the transport demand presented. The influence of factors such as the development of economics, level of motorization, inhabitant density and land use on the transport demand are evaluated. Analysis is performed on the basis of the theoretical expressions of inhabitant mobility and the information of practical investigations.
\end{abstract}

Keywords: sustainable city, public transport, mobility, land use, urban planning.

\section{Introduction}

With about three-quarters of the population of the European Union living in urban areas, most transport related environmental and health problems occur in cities and surrounding areas [1]. Increased use of public transport is one of the keys to sustainable mobility. Achieving this increase depends on linking all forms of travel in ways that also create better living conditions with less air and noise pollution, and less use of land and energy.

The relationships between land-use and transport are complex, as each is directly dependent on the other. The difficulty is compounded by interactions with other factors, such as age of distribution, employment categories, income levels and car ownership, which may both depend on, and be influenced by, 
land-use and transport characteristics. It is therefore difficult to establish the precise relationships between public transport demand and land-use patterns.

Urban transport has a direct impact on air pollution and noise. Cities of EUmember states adopt plans on a voluntary basis to improve the quality of life or in order to comply with EU standards to protect human health. Engineering, organizational and administrative air pollution and noise reducing measures are also reviewed along with effects considered harmful to human health [2-4].

In the development and implementation of sustainable urban transport plans safety and security, access to goods and services, air pollution, noise, greenhouse gas emissions and energy consumption, land use, cover passenger and freight transportation and all modes of transport are considered.

Land use and transportation are two sides of the same coin. The creation of the strategy of sustainable urban transport development requires the use of a method taking into account land-use planning and social-economic development. This paper investigates how development of economics, level of motorization, inhabitant density and land use affect travel behavior.

\section{Evaluating the influence of land use and socio-economic development on transport demand}

The influence of the main parameter of transport planning - mobility of inhabitants - is considered with three factors [5]:

- distance of area to city centre $D_{c}$,

- coefficient of specializations of workplaces of the area $\lambda$,

- coefficient of the general specialization of the area $\lambda^{*}$.

The general statistical influence of the primary factors $D_{c}$ and $\lambda$ on mobility of inhabitants is considered through the equation of regress:

$$
m=2.413+0.129 D_{c}+0.518 \lambda
$$

Including territorial urban development by inevitable necessity, the important factor is one of the features of urban structure - specialization of workplaces $\lambda$. Having an increase $\Delta=1.5$, the mobility of inhabitants increases up to 0.53 travel/day per inhabitant: $m=2.870+0.518 \lambda$. This difference corresponds 20 $30 \%$ of all capacity of the urban transport system. Such additional transport demand is considered as a mistake of urban planning.

From the viewpoint of modern transport strategy, this mistake increases with redistribution of transport modes, caused by factors of territorial development and specialization of urban areas [1].

Moving away from the city centre and with an increase in specialization of workplace areas, a decrease is seen on the part of the pedestrian travel of the general mobility:

$$
m_{p}=59.432-0.122 A-1.132 D_{c}-5.723 \lambda
$$

The value of the pedestrian travel reduces the level of motorization $A$. 
With an increase in the specialization of workplaces, the travel by individuals own cars is increased:

$$
m_{c}=4.921+3.836 \lambda
$$

With removal from the city centre and with increase of workplace areas and the level of motorization, the demand of all transport modes (individuals own cars, buses, trolley buses) increases:

$$
m_{t}=38.723+0.179 A+1.103 D_{c}+6.487 \lambda
$$

Analyzing the data from scientists of institutes of transport (Kaunas University of Technology) leads to interrogations of the mobility of inhabitants of the biggest Lithuanian cities $[6,8]$ and the influence of urbanity factors on transport demand, that is, the level of specialization of areas and the attitude of the number of inhabitants and workplaces.

The demand of the main transport modes is defined by the regress equation:

$$
m_{t}=0.875+0.493 \lambda+0.132 \lambda^{*}+0.486 \log 10 k
$$

Analyzing the data of the investigations, it is established that the main factors of urban structure and the development of urban territory $L_{c}$ for a level of mobility $m_{t}$ became significant. It is the important fact, allowing formulating such hypothesis - to development of urban territory having exceeded the certain limit, self-regulation of transport demand, which reduces influence of urban factors, begins and practically cancels influence of land-use on transport mobility of inhabitants. There are some arguments of such a hypothesis.

Table 1: Correlation of average travel time of inhabitants with urbanity factors.

\begin{tabular}{|c|c|c|c|c|}
\hline \multirow{2}{*}{ Transport mode } & \multicolumn{4}{|c|}{ Correlation coefficient $r$} \\
\cline { 2 - 5 } & $\lambda$ & $\lambda^{*}$ & $D_{c}$ & $\log 10 k$ \\
\hline Pedestrian & -0.065 & -0.320 & 0.025 & -0.484 \\
Public transport & 0.489 & 0.675 & 0.613 & 0.702 \\
Own car & 0.020 & 0.010 & 0.231 & 0.108 \\
\hline
\end{tabular}

Without the process of demand regulation (together with the redistribution of communications), the time of journey of inhabitants should depend on the factor of territory development directly. However, this dependence is really for travel by public transport (Table 1), that is to that transport mode which has the minimal opportunities of redistribution of communications of inhabitants and service of peripheral areas. 
That time of pedestrian travel and by own car does not depend either on the factor of territory development, nor from factors of urban structure, shows that there is a redistribution of communication by a principle of minimization of duration of travel. It accompanied with change of a place of work and residing, a free choice of services in the developed network of the enterprises of services sphere. The increased in the number of cars also changes life style - the socalled chain of the purposes of one travel extended. For time minimization of travel, escalating value of own and service cars for service of inhabitants of a peripheral zone has an important role.

With the increase of area specialization and a disproportion of workplaces of inhabitants, the opportunity of pedestrian travel decreases. At the same time, the travel demand by public transport increases. In that case the competition of own cars, especially in the inhabitants group of 35-49 years age appears. For mobility of this group of inhabitants, the specialization factor is statistically insignificant.

Set of inhabitants travel is a more characteristic parameter for the analysis of the urbanity factors, rather than the separate analysis of pedestrian travel, travel on public transport and own car. It means that the transport mode is less determined in space and in time and gives the greatest freedom and speed of transportation; it is less influenced by functional urban structure on transport demand.

Table 2: Relative influence of urbanity factors on mobility of inhabitants of 25-34/35-49 years age.

\begin{tabular}{|c|c|c|c|}
\hline \multirow{2}{*}{ Transport mode } & \multicolumn{3}{|c|}{ Change of urbanity factors $\Delta=+15 \%$} \\
\cline { 2 - 4 } & $\lambda$ & $\lambda^{*}$ & $\log k$ \\
\cline { 2 - 4 } & \multicolumn{3}{|c|}{ Change of mobility of inhabitants $\pm \%$} \\
\hline Pedestrian & $+2.5 /-2.1$ & $-5.2 /-2.9$ & $-0.3 /-1.3$ \\
Public transport & $+1.3 /-0.6$ & $+1.1 /+4.1$ & $+3.2 /+2.7$ \\
Own car & $-0.3 /-0.2$ & $+3.4 /-0.1$ & $+0.9 /+1.4$ \\
\hline
\end{tabular}

Factors of urban territorial and functional development have caused unfortunate trends of the demand of pedestrian and public transport travel and least influenced demand of travel by own car. Range of numerical values of urbanity factors including equal $100 \%$, it is possible to calculate their correlative influence on mobility of inhabitants (Table 2).

Results of the analysis of mobility of inhabitants have shown that land-use is the important factor and over time can cause demand and influence the structure of transport.

To rates of urban territorial development there corresponds low rates of demand in growth of public transport. To those inhabitants who use public transport, the environment of activity is limited; represented services are compelled to limit the system of demand, in a field of activity from low speed of the transportation, density and a branching of a routing network. Then, the urban 
areas are more specialized, with more disproportionate places of work and residences, or is more remote from a city centre with the average routes of public transport at times shown below, and the routing network becoming less convenient and coherent.

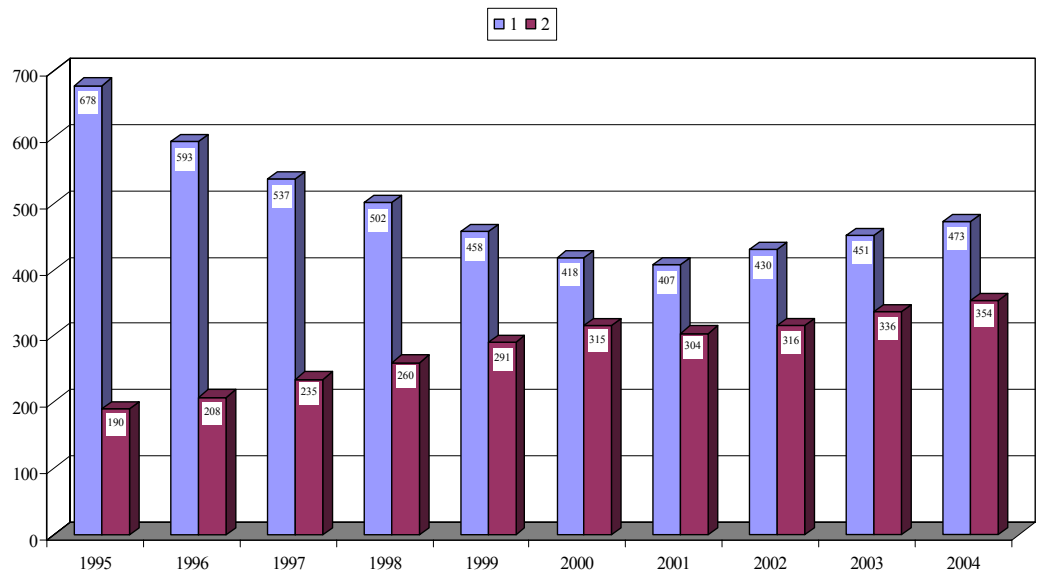

Figure 1: $\quad$ Change of number by public transport transported passengers -1 and numbers of cars on 1000 inhabitants -2 [7].

The peripheral area and specialized areas served by pulsing in the present day are opportunities given by public transport, the corresponding variable character of travel of inhabitants and working in these areas. Service by public transport is not qualitative and guaranteed, making an increase of the value of using one's own car a compulsory phenomenon where there are no other alternatives. The tendency of the role of public transport in Lithuanian cities is presented in Fig. 1.

The gain of real demand of the all transport modes is more than the scale of urban territorial development. This is a consequence of mobilization. The escalating number of cars has given on opportunity to inhabitants to freely choose a field of activity. This opportunity has shown a true transport demand.

\section{Conclusions}

The results of inhabitants mobility analysis has shown that the main factor in urban transport policy enables us to predetermine its infrastructure and the demand of land-use. The construction of low-storeyed houses prevailing in Lithuanian Cities predetermined the increased in transport demand and more opportunities for own transport means.

Unsustainable land-use forms through functional specialization of urban areas, disproportions of numbers of inhabitants and workplaces, a non-uniform allocation of the service sphere, forms negative processes:

- raises the general transport demand $-25-30 \%$ of travel are compulsory,

- reduces opportunities of pedestrian travel 3-4 times, 
- $\quad$ raises demand of travel by own cars 1.7-2.2 times,

- transforms demographic structure of inhabitants,

- forms non-uniformity of loading of a network of streets and transport routes up to 8-9 times.

During the last ten years the number of passenger conveyed by public transport decreased by $30 \%$. In the same time, the number of personal cars per 1000 residents increased from 190 cars in 1995 to 354 cars in 2004. It is not only the result of an improved economics situation. The choice of own transport means is associated with the negative aspects of public transport.

Prompt mobilization was the main reason, destroyed dynamic balance of urban structure and transport systems. Having decreased the value of public transport in transport structure and with an increase in using own cars, 3-4 times the need of territories for a parking and storage of cars has increased, 3 times relative consumption of fuel, air pollution and noise levels, probability of transport incidents has grown, speed of transport flows has decreased.

According to travel receptivity, the relation of significance between public transport and own transport means, the dynamics of the motorization level, the development of the processes that occurred in EU-15 member-countries for 20 years are repeated in Lithuanian cities.

As a means to gaining efficient, sustainable urban transport, the integration of public transport planning and land-use planning is necessary.

\section{References}

[1] Macario, R., Carvalho, D. \& Fermisson, J. Achieving sustainable transport and land use with integrated policies. Proc. of the $11^{\text {th }}$ Int. Conf. Urban Transport and the Environment in the $21^{\text {st }}$ Century, eds. C.A. Brebbia \& L.C. Wadhwa, WIT Press: Southampton, Boston, pp. 351-360, 2005.

[2] Bazaras, Z. Simulation of noise emission in the railway traction means. Proc. of the $11^{\text {th }}$ Int. Conf. Urban Transport and the Environment in the $21^{\text {st }}$ Century, eds. C.A. Brebbia \& L.C. Wadhwa, WIT Press: Southampton, Boston, pp. 521-530, 2005.

[3] Bazaras, Z., Kucinovas, M. \& Povyshev, I. Simulation of noise emission in the railway traction means. Proc. of Int. Conf. Transport means 2004, Technologija: Kaunas, pp. 65-71, 2004.

[4] Boarnet, M. \& Crane, R. The influence of land use on travel behavior: specification and estimation strategies. Journal of Transportation Research, Elsevier, Part A 35, pp. 823-845, 2001.

[5] Oppenheim, N. Urban Travel Demand Modeling. New York: John Wiley \& Sons, 1995.

[6] General urban transport plan for Lithuanian cities. Final Report. COWI Consulting engineers and planners AS. Head Mr. Vilhof, P., 1997.

[7] Statistics Lithuania: http://www.std.lt/en .

[8] Public transport in Kaunas city: Report of the interrogations of inhabitants. Urban development and transport department of Kaunas Municipality, 2005 (http://www.kaunas.lt/en , http://www.VIVALDIproject.org ). 